\title{
Dynamics of T Lymphocyte between the Periphery and the Brain from the Acute to the Chronic Phase Following Ischemic Stroke in Mice
}

\author{
Minha Kim ${ }^{1 \dagger}$, So-Dam Kim ${ }^{2 \dagger}$, Kyoung In Kim³, Eun Hae Jeon ${ }^{1,4}$, Min Gee Kim², Yu-Ree Lim ${ }^{1}$, \\ Enkhmaa Lkhagva-Yondon ${ }^{1,4}$, Yena $\mathrm{Oh}^{1}$, Kwangmin $\mathrm{Na}^{1}$, Young Cheul Chung ${ }^{3}$, Byung Kwan Jin ${ }^{3}$, \\ Yun Seon Song ${ }^{2 *}$ and Myung-Shin Jeon ${ }^{1,4,5 *}$ \\ ${ }^{1}$ Translational Research Center, Department of Molecular Biomedicine, IRIMS, and College of Medicine, Inha University, \\ Incheon 22332, ${ }^{2}$ College of Pharmacy, Sookmyung Women's University, Seoul 04310, \\ ${ }^{3}$ Department of Biochemistry \& Molecular Biology, School of Medicine, Kyung Hee University, Seoul 02447, \\ ${ }^{4}$ Program in Biomedical Science and Engineering, Graduate School, Inha University, Incheon 22332, \\ ${ }^{5}$ Convergent Research Center for Metabolism and Immunoregulation, Inha University, Incheon 22212, Korea
}

\begin{abstract}
Stroke causes systemic immunosuppression. T lymphocytes are involved in infarct size in the early stages of stroke. However, the phenotypes of T lymphocytes and their functions in peripheral immune organs and the brain have not been well analyzed in the acute and chronic phases of stroke. Here, we investigated pathological phenotypic alterations in the systemic immune response, especially changes in T lymphocytes, from one day to six months after ischemic stroke in mice. Impairment in thymocyte numbers, development, proliferation, and apoptosis were observed for up to two weeks. The number of mature T cells in the spleen and blood decreased and showed reduced interferon- $\gamma$ production. Increased numbers of $\mathrm{CD} 4 \mathrm{CD} 8 \mathrm{CD}^{+}$double-negative $\mathrm{T}$ cells were observed in the mouse brain during the early stages of stroke, whereas interleukin (IL)- $10^{+} \mathrm{Foxp} 3^{+}$ regulatory T lymphocytes increased from two weeks during the chronic phase. These phenotypes correlated with body weight and neurological severity scores. The recovery of T lymphocyte numbers and increases in IL- $10^{+}$Foxp $3^{+}$regulatory T lymphocytes may be important for long-term neurological outcomes. Dynamic changes in T lymphocytes between the acute and chronic phases may play different roles in pathogenesis and recovery. This study provides fundamental information regarding the T lymphocyte alterations from the brain to the peripheral immune organs following stroke.
\end{abstract}

Key words: Ischemic stroke, T lymphocytes, Thymocyte, IL-10, Foxp3, Regulatory T cells

Submitted December 17,2020, Revised March 3,2021,

Accepted March 3, 2021

* To whom correspondence should be addressed.

Myung-Shin Jeon, TEL: 82-32-890-3682, FAX: 82-32-890-2462

e-mail:msjeon@inha.ac.kr

Yun Seon Song, TEL: 82-2-2077-7231, FAX: 82-2-710-9871

e-mail:yssong@sookmyung.ac.kr

${ }^{\dagger}$ These authors contributed equally to this article.

\section{INTRODUCTION}

Ischemic stroke occurs when blood flow to the brain is blocked. Without oxygen and glucose, neurons undergo cell death. The process of cell death in the brain following a stroke leads to the activation of local immune cells, causing inflammation of the brain tissue. Inflammation plays an important role in the pathogenesis of ischemic stroke [1]. Clinically, the susceptibility of patients to stroke and subsequent prognosis is influenced by systemic inflammatory processes $[2,3]$. Patients that suffer a stroke with systemic 
inflammation exhibit poor clinical outcomes $[4,5]$. Peripheral immune cells are involved in systemic inflammation. Animal studies and clinical data consistently reveal a drastic shrinkage in spleen size following stroke, which is accompanied by a reduction in the number of splenocytes $[6,7]$. Further studies have reported that splenectomy prior to middle cerebral artery occlusion (MCAO) in both rats and mice resulted in decreased infarct volume and improved behavioral deficits up to $96 \mathrm{~h}$ after stroke $[8,9]$, indicating a pathological role of splenocytes in the acute phase of stroke. Lymphocyte-deficient $\operatorname{Rag}^{-1^{-}}$and SCID mice showed sustained small infarct volumes and improvements in neurologic deficits within $24 \mathrm{~h}$ of MCAO $[10,11] . \mathrm{CD}^{+}$or $\mathrm{CD}^{+} \mathrm{T}$ lymphocyte deficiency decreases the infarct volume after stroke [11], indicating that $\mathrm{T}$ lymphocytes play a pathological role in acute ischemic stroke.

Several previous studies have focused on the early stages of stroke, between 24 and $96 \mathrm{~h}$. The phenotypes of $\mathrm{T}$ lymphocytes in the acute and chronic phases of stroke have not yet been fully elucidated. Therefore, we focused on the pathological phenotype of systemic immune alterations and neurological behavior, especially those of $\mathrm{T}$ lymphocytes from one day to six months after stroke.

\section{MATERIALS AND METHODS}

\section{Animals}

Male C57BL/6 mice (10 12-weeks old) were used in this study (Orient, Seongnam, South Korea). The mice were housed in a specific pathogen-free barrier facility at Inha University, Incheon, South Korea. All animal experiments were approved by the Institutional Animal Care and Use Committee (INHA 170908-513-1).

\section{Transient MCAO (tMCAO) stroke model}

The tMCAO stroke model was induced via MCAO using a 6-0 nylon monofilament suture (Doccol Corporation, Sharon, MA, USA). Briefly, the mice were anesthetized using $2 \%$ isoflurane (Kyongbo Pharmaceutical Co. Ltd, Asan, South Korea) in conjunction with 30\% oxygen and 70\% nitrous oxide using a face mask. The mice were placed on a heat pad throughout the procedure. After anesthetization, a midline neck incision was made. The left common carotid artery (CCA), internal carotid artery (ICA), and external carotid artery (ECA) were exposed. One knot was made around the CCA, and two were made in the ECA. After cutting between the two knots in the ECA, a suture with a round, coated tip (filament size 6-0, diameter 0.09 0.11 mm, length 20 $\mathrm{mm}$; diameter of coated tip $0.25 \pm 0.02 \mathrm{~mm}$, length $5 \sim 6 \mathrm{~mm}$; Cat\# 602556PK10Re; Doccol Corporation, Sharon, MA, USA) was inserted into the ECA lumen, gently advanced into the ICA lumen to block MCA blood flow and left there for $45 \mathrm{~min}$, until reperfusion.
In sham-operated mice, after incision of the skin and exposure of blood vessels (as in tMCAO), a knot was made in the CCA. After $10 \mathrm{~min}$, the knot was removed and the skin was sutured. Mice were euthanized at various time points. We analyzed naive, sham, and tMCAO group at one day, one week, two weeks, two months, and six months post-tMCAO. As we did not observe significant differences between the naive and sham groups, we compared the data for tMCAO group with those for the sham group. The animals that showed incomplete infarction as tested by cresyl violet staining or those that either did not show circling behavior or suddenly died immediately after the surgery were excluded in the study. The overall survival rate up to six months was approximately $68.5 \%$.

\section{Neurological severity score (NSS)}

The NSS was determined and recorded using the following four parameters.

\section{Zea-longa 5-point score}

The Zea-longa score was determined by observing movements of the mice in and out of the cage: 0 , mice with no neurological deficits; 1 , mice could not fully extend the left forepaw; 2 , mice circled to the left while walking; 3 , mice fell to the left or limped; and 4 , mice were unable to walk spontaneously; 5 , death [12].

\section{Prehensile traction 4-grade score}

We determined the ability of the mice to grab and hold onto a 0.5 $\mathrm{cm}$ diameter wire elevated at a height of $70 \mathrm{~cm}$ from the surface. Performance was evaluated using a four-grade score: 0 , mice could hang on the wire for over $5 \mathrm{~s}$ with hind legs placed on the wire; 1 , mice could hang on the wire for $5 s ; 2$, mice could hang on the wire for 3 4 s; and 3, mice could hang on the wire for $0 \sim 2 \mathrm{~s}$. For scores $1 \sim 3$, the mice were unable to place their hind legs on the wire [13].

\section{Circling 5-point score}

Circling behavior was determined by observing and scoring the ability of the mice to remain in contact with the floor with their forelegs: 0 , mice had no observable deficits; 1 , mice exhibited flexion of the contralateral torso; 2 , mice circled clockwise; 3 , mice continuously spun clockwise; and 4, no movements or reactions [14].

\section{Forelimb 5-point score}

The mice were held by their tail, and the bending of the torso or forelimbs in the air was observed and scored: 0 , normal reaction; 1 , mice occasionally exhibited flexion of the asymmetric forelimb; 2 , asymmetric forelimb flexion; 3 , mice exhibited flexion of the asymmetric forelimb and torso; and 4, no motor activity or reac- 
tion [14].

\section{Cresyl violet staining}

Brains were fixed using 4\% paraformaldehyde (PFA; Biosesang, Seongnam, South Korea), and the sections were stained with $0.1 \%$ cresyl violet (Sigma-Aldrich, St. Louis, MO, USA) in distilled water. The infarct areas were measured using ImageJ software (NIH, Bethesda, MD, USA).

\section{Flow cytometric analysis of cell populations in the blood, spleen, and thymus}

After anesthesia, blood was collected via retro-orbital bleeding using sterile capillary tubes (Paul Marienfeld GmbH \& Co. KG., Lauda-Königshofen, Germany). The blood samples $(50 \mu \mathrm{L})$ were stained using fluorescence-activated cell sorting (FACS) antibodies at $4^{\circ} \mathrm{C}$ for $20 \mathrm{~min}$; then, the red blood cells (RBCs) were removed using RBC lysis buffer (Sigma-Aldrich). The samples were washed once with FACS buffer (phosphate-buffered saline [PBS] with $1 \%$ bovine serum albumin [BSA] and $20 \mathrm{mM}$ ethylenediaminetetraacetic acid) and fixed using 4\% PFA. Additionally, lymphocytes $\left(1 \times 10^{6}\right)$ from the spleen and thymus were incubated with FACS antibodies at $4^{\circ} \mathrm{C}$ for $20 \mathrm{~min}$. The cells were rinsed once with FACS buffer and fixed using 4\% PFA. Cells were then analyzed using flow cytometry (BD FACS Verse ${ }^{\mathrm{TM}}$; BD Biosciences, San Jose, CA, USA), and FlowJo software (BD Biosciences) was used for data analysis. FACS antibodies anti-CD3 (145-2C11), anti-CD4 (RM45, GK1.5), anti-CD8 (53-6.7), anti-CD44 (IM7), anti-CD25 (3C7), anti-CD45R/B220 (RA3-6B2), and anti-T cell receptor (TCR)- $\beta$ (H57-597) were purchased from BD Biosciences. Anti-CD3 (17A2) antibody was purchased from BioLegend (San Diego, CA, USA). Anti-CD8 (5H10) and anti-CD62L (MEL-14) were purchased from Invitrogen (Carlsbad, CA, USA).

\section{In vivo thymocyte proliferation assay using 5-bromo-2-de- oxyuridine (BrdU)}

One day after tMCAO, $150 \mu \mathrm{L}$ of $\mathrm{BrdU}(10 \mathrm{mg} / \mathrm{ml})$ (BD Biosciences) was injected intraperitoneally to the $\mathrm{TCAO}$ and sham mice. The thymus was retrieved $2 \mathrm{~h}$ later, and BrdU-positive cells were analyzed using a BrdU assay kit according to the manufacturer's protocol (BD Biosciences).

\section{Cell culture and cytokine analysis using enzyme-linked im- munosorbent assay (ELISA)}

First, $1 \times 10^{6}$ lymphocytes from the spleen were stimulated with $0.1 \mu \mathrm{g} / \mathrm{ml}$ of anti-CD3 (145-2C11) and anti-CD28 (37.51) antibodies (BioGems, Westlake Village, CA, USA) in Roswell Park Memorial Institute (RPMI) 1640 (HyClone, GE Healthcare Life
Science, PA, USA) culture medium containing 0.1\% 2-mercaptoethanol (Thermo Fisher Scientific, Waltham, MA, USA), 10\% heat-inactivated fetal bovine serum (FBS; Gibco ${ }^{\circledR}$, Australia origin, Thermo Fisher Scientific), and 1\% antibiotic-antimycotic (Thermo Fisher Scientific) in a 24 -well plate and incubated at $37^{\circ} \mathrm{C}$ in a $5 \%$ $\mathrm{CO}_{2}$ incubator. After 24 and $48 \mathrm{~h}$ of stimulation, interleukin (IL)2 , IL-4, IL-13, and interferon (IFN)- $\gamma$ levels in the culture medium were quantified using ELISA kits according to the manufacturer's protocol (BD Biosciences).

\section{Isolation of T lymphocytes from the brain}

T lymphocytes from the brain were isolated as described previously, with some modifications [15]. A Percoll gradient protocol was used. The stock isotonic Percoll (SIP) was prepared by mixing nine parts of Percoll (Sigma-Aldrich) with one part of $10 \times$ Dulbeccos PBS (DPBS) without calcium chloride or magnesium sulfate. Each hemisphere of the brain was minced using a homogenizer in a $1.5 \mathrm{ml}$ tube with RPMI 1640 containing 0.1\% 2-mercaptoethanol, 10\% FBS, and 1\% antibiotic-antimycotic. Digestive enzymes, including collagenase type I ( $2 \mathrm{mg} / \mathrm{ml}$, Sigma-Aldrich) and DNase type II ( $40 \mu \mathrm{g} / \mathrm{ml}$, Sigma-Aldrich) in $1 \times$ DPBS were added after homogenization and incubated at $37^{\circ} \mathrm{C}$ for $45 \mathrm{~min}$. The cell suspension was then passed through a $70 \mu \mathrm{m}$ cell strainer and rinsed with $1 \times$ DPBS, and the volume was made up to $7 \mathrm{ml}$. Next, $3 \mathrm{ml}$ of SIP was added to the cell suspension to obtain a final concentration of $30 \%$ SIP. The cell suspension ( $10 \mathrm{ml}$ in $30 \% \mathrm{SIP}$ ) was layered on top of $2 \mathrm{ml}$ of $70 \%$ SIP in a $15-\mathrm{ml}$ conical tube to make a total volume of $12 \mathrm{ml}$. After centrifugation at 2,000 rpm for $20 \mathrm{~min}$ at room temperature (RT), $3 \sim 4 \mathrm{ml}$ of the white layer at the 70 30\% interface was collected in a new tube. After further centrifugation at 1,500 rpm for $3 \mathrm{~min}$, the cells were rinsed once with FACS buffer or $1 \times$ PBS. To perform FACS analysis of the brain $T$ lymphocytes, two to four independent $\mathrm{tMCAO}$ experiments were conducted; the number of independent experiments was three at one day and two weeks and four at one week. The brain contained a very low number of $\mathrm{T}$ lymphocytes, especially in the sham group, and several brains were pooled and the data per brain were calculated.

\section{Immunohistochemistry}

Mice were transcardially perfused with saline solution containing $0.5 \%$ sodium nitrate and heparin $(10 \mathrm{U} / \mathrm{ml})$, and then fixed using 4\% PFA dissolved in $0.1 \mathrm{M}$ phosphate buffer. Brain tissues were dissected from the skull, post-fixed overnight in buffered $4 \%$ PFA at $4^{\circ} \mathrm{C}$, and stored in a $30 \%$ sucrose solution for $24 \sim 48 \mathrm{~h}$ at $4^{\circ} \mathrm{C}$ until they were settled, frozen, and sectioned on a cryostat in $30-\mu \mathrm{m}$-thick coronal sections. Tissue sections were washed in cold 
PBS three times for 10 min and blocked with a universal blocking solution ( $0.3 \%$ Triton $^{\mathrm{TM}} \mathrm{X}-100,1 \%$ BSA, $0.05 \%$ Tween 20 , and $0.05 \%$ sodium azide in PBS) for $1 \mathrm{~h}$ at RT. Sections were then incubated with the following primary antibodies: rat anti-Foxp3 (1:100, Invitrogen) and anti-IL-10 (1:90, R\&D system, Minneapolis, MN, USA) for $2 \mathrm{~h}$ at RT. Thereafter, the tissues were rinsed and incubated with Alexa Fluor 488 donkey anti-rabbit IgG (1:400, Invitrogen) and Alexa Fluor 594 goat anti-mouse IgG (1:400, Invitrogen) for $1 \mathrm{~h}$. After washing with PBS, coverslips were mounted on glass slides using mounting media with DAPI (Vector Laboratories, Burlingame, CA, USA) and analyzed using a confocal microscope (LSM 800, Carl Zeiss, Oberkochen, Germany). For CD4 staining, the tissues were stained with rabbit anti-CD4 antibody (1:400, Santa Cruz Biotechnology, Dallas, TX, USA) at $4{ }^{\circ} \mathrm{C}$ overnight. The following day, tissues were rinsed and incubated with Cy3-conjugated-anti-rabbit IgG (1:800, Millipore, Burlington, MA, USA) for $1 \mathrm{~h}$. Labeled tissue sections were mounted on gelatin-coated slides and analyzed under a confocal microscope (LSM 700, Carl Zeiss).

\section{Statistical analyses}

For the analysis of peripheral lymphocytes and behavior, one to three independent tMCAO experiments were performed at each time point. Experiments were performed three times on one day, two weeks, and two months after stroke; twice at one week; and once at six months. The data presented in Figures were pooled data from all experiments and expressed as the mean \pm SD. The exact numbers of mice used are described in the figure legends. Student's t-tests were used to compare independent groups of data. $p$ values of ${ }^{*} \leq 0.05,{ }^{* *} \leq 0.01$, and ${ }^{* *} \leq 0.001$ were considered significant.

\section{RESULTS}

\section{Evaluation of infarct area and neurological impairment from one day up to six months in $\mathrm{TMCAO}$ mice}

First, we evaluated the infarct volume from day one to six months. Brain damage after tMCAO was measured using cresyl violet staining. The extent of brain damage was evaluated as a percentage of the infarct area in the acute phase (one day and one week) and as atrophy in the chronic phase (two weeks, two months, and six months) after tMCAO. As stroke causes atrophy in the chronic phase, the brain volume representing non-injured tissue (NI), ischemic scar tissue (IS), remaining total ipsilateral tissue T $(\mathrm{NI}+\mathrm{IS})$, and resorbed tissue (estimated infarct: EI) was analyzed according to a previously reported method [16]. We found that cerebral ischemia caused an infarction that peaked at one week (Fig. 1 A and B). In addition, the neurological impairment status of tMCAO mice was assessed using NSS at different time points. Compared with the sham mice, the tMCAO mice showed decreased body weight and neurological dysfunction in the four parameters of NSS for up to two weeks (Fig. 1C and D). Sustained neuronal atrophy was observed between two and six months (Fig. 1B). Improvements in animal body weight and behavior were observed after two weeks.

\section{Impairment of thymocyte development in tMCAO mice}

Although thymus shrinkage occurs in the early stages of stroke [6, 17], long-term changes in phenotypes have not been analyzed in tMCAO mice. Here, we evaluated the phenotypes of thymocytes from one day to six months after stroke. Strong thymic shrinkage was observed in tMCAO mice (Fig. 2A). The number of thymocytes in tMCAO mice was significantly lower than that in sham mice from one day to two weeks after stroke, which gradually recovered to the same levels as observed in sham mice after two months (Fig. 2B). The thymocyte subpopulation is well-defined according to CD4 and CD8 expression: double-negative (DN: $\mathrm{CD} 4 \mathrm{CD} 8^{-}$), double-positive (DP: $\mathrm{CD} 4^{+} \mathrm{CD} 8^{+}$), and single-positive $\left(\mathrm{CD} 4^{+} \mathrm{CD} 8^{-}\right.$or $\left.\mathrm{CD} 4 \mathrm{CD}^{+}\right)$. The DP subpopulation percentage dramatically decreased one week after tMCAO mice (Fig. 2C). The absolute cell number in each subpopulation was significantly reduced until two weeks after stroke (Fig. 2D). Although stroke induces apoptosis by releasing stress hormones [17], we found that this may not be the only explanation for thymic shrinkage in tMCAO mice. The thymocyte development process was identified based on the expression of specific cell surface markers, such as CD4, CD8, CD44, and CD25. The DN population was divided into four stages: DN1 (CD44 $\left.{ }^{+} \mathrm{CD} 25^{-}\right)$, DN2 (CD $\left.44^{+} \mathrm{CD} 25^{+}\right)$, DN3 $\left(\mathrm{CD} 44^{-} \mathrm{CD} 25^{+}\right)$, and DN4 (CD44CD25). The population of DN1 was approximately $40 \%$ higher in tMCAO mice than in the sham group one week after stroke, whereas the $\mathrm{DN} 4$ population was approximately 25\% lower (Fig. 3A and B). These results suggest that stroke may arrest development from DN1 to DN2. As the thymus produces thymocytes daily, and a certain number of thymocytes mature and seen in peripheral circulation, we analyzed whether stroke inhibited thymocyte proliferation. BrdU was injected into the mice one day after tMCAO, and BrdU-positive thymocytes were analyzed using flow cytometry. As shown in Fig. 3C, stroke completely blocked the proliferation of thymocytes. Furthermore, we found that the population of TCR- $\beta^{+}$thymocytes in the DN stage was approximately 25\% higher than that in the sham mice one week after stroke (Fig. 3D and 3E). Thymocytes that do not undergo appropriate TCR rearrangement undergo apoptosis, whereas those that express appropriate TCRs interact with peptides, determining the positive and negative selection essential for 


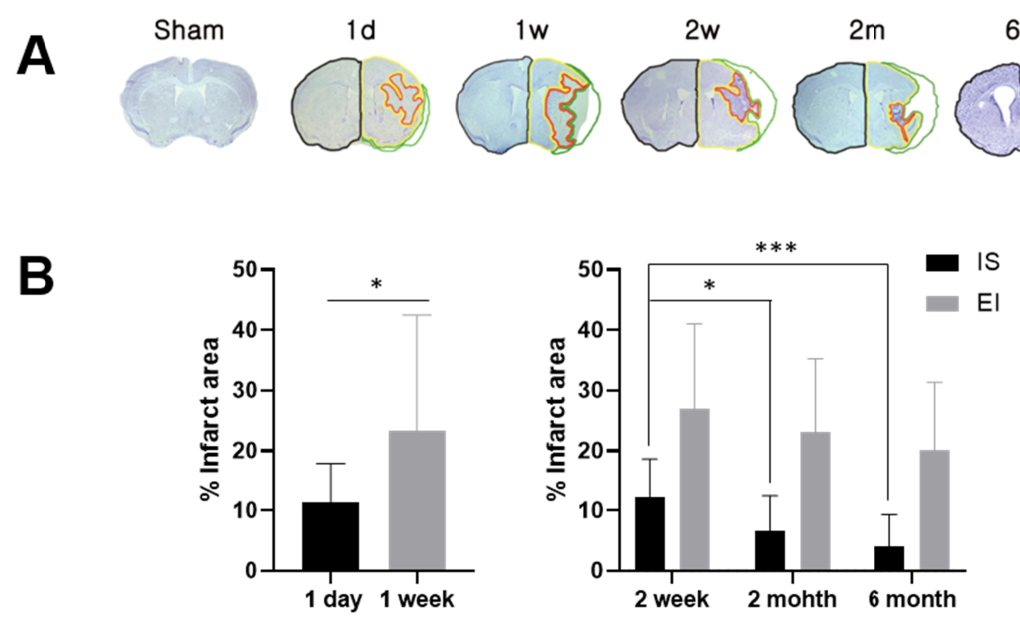

C

\section{Body weight}
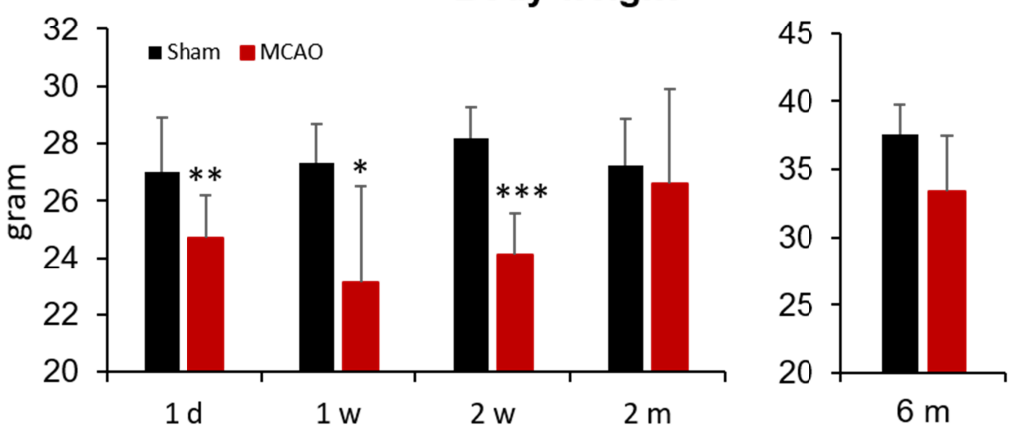

D
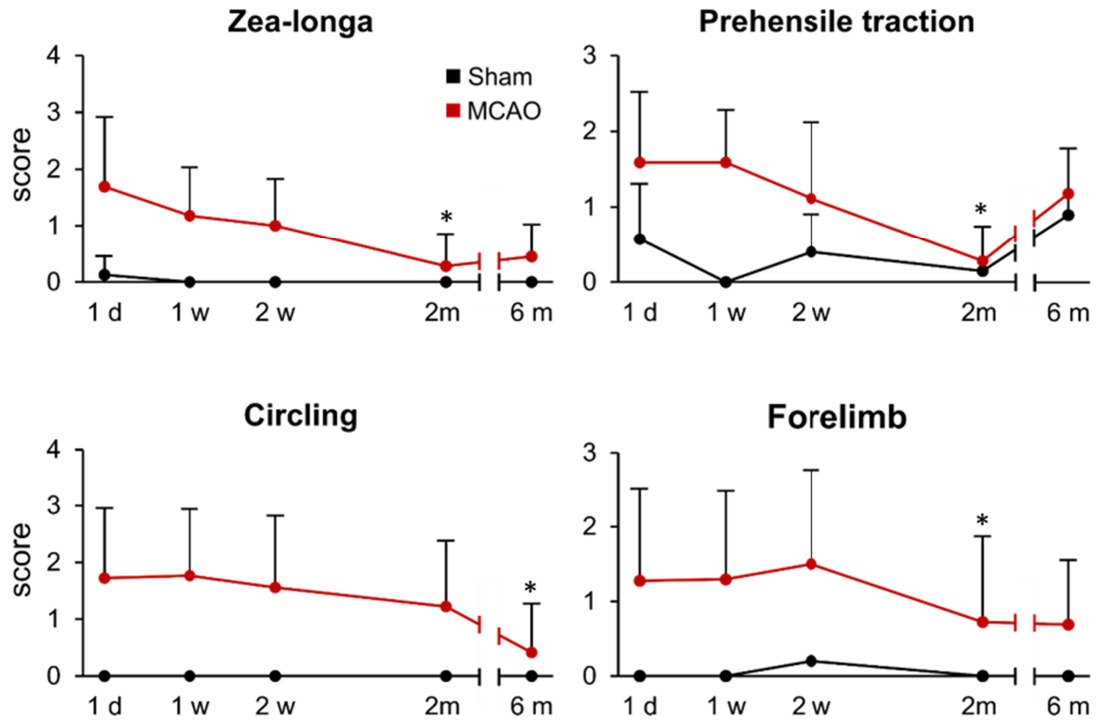

Fig. 1. Measurements of infarct volume, body weight, and NSS after tMCAO. (A, B) Assessment of tissue volume from one day to six months after tMCAO. NI (non-injured tissue, yellow); IS (ischemic scar tissue, red); T (total ipsilateral tissue=NI+IS); EI (estimated infarct tissue) was calculated by subtracting total ipsilateral volume from total contralateral volume (black line) (namely differences between the hemispheres, green). Numbers of tMCAO mice at $1 \mathrm{~d}(\mathrm{n}=9), 1 \mathrm{w}(\mathrm{n}=7), 2 \mathrm{w}(\mathrm{n}=11), 2 \mathrm{~m}(\mathrm{n}=13)$, and $6 \mathrm{~m}(\mathrm{n}=10)$. (C) The body weights were measured. Numbers of mice were ( $\mathrm{n}=$ sham/tMCAO): 1 $d(n=8 / 17), 1 \mathrm{w}(\mathrm{n}=5 / 12), 2 \mathrm{w}(\mathrm{n}=5 / 11), 2 \mathrm{~m}(\mathrm{n}=7 / 18)$, and $6 \mathrm{~m}(\mathrm{n}=9 / 29)$. $\mathrm{p}$ values were determined using a two-tailed Student's $\mathrm{t}$-test. ${ }^{*} \mathrm{p} \leq 0.05,{ }^{* *} \mathrm{p} \leq 0.01$, and ${ }^{* * *} p \leq 0.001$. (D) Evaluation of neurological impairment using NSS. The scores of the mice assessed at each time point were averaged. Number of mice were ( $\mathrm{n}=$ sham/tMCAO): $1 \mathrm{~d}(\mathrm{n}=8 / 29), 1 \mathrm{w}(\mathrm{n}=5 / 17), 2 \mathrm{w}(\mathrm{n}=5 / 9), 2 \mathrm{~m}(\mathrm{n}=7 / 18), 6 \mathrm{~m}(\mathrm{n}=9 / 29)$. Data were compared with that on day one after stroke: ${ }^{*} \mathrm{p} \leq 0.05$. 
A

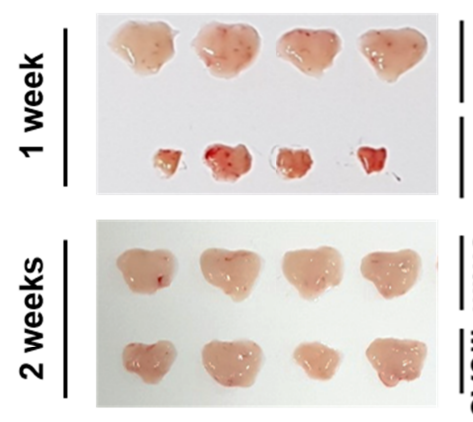

B

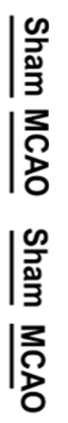

\section{Thymus}

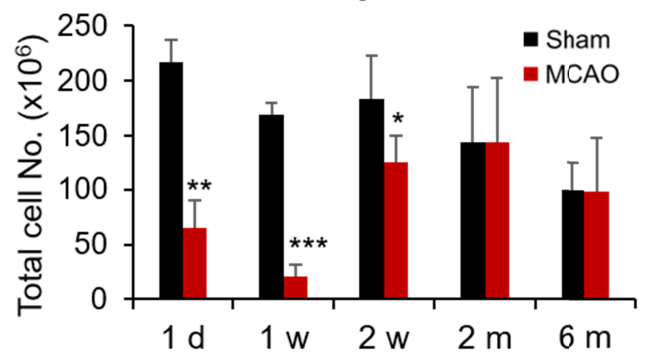

C
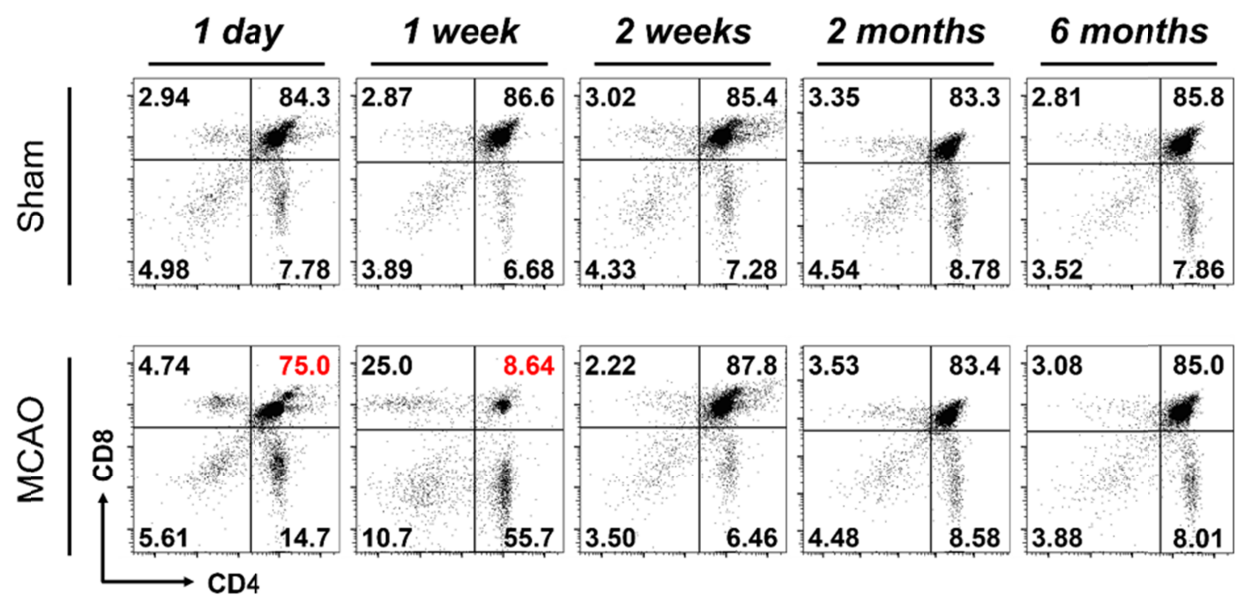

D
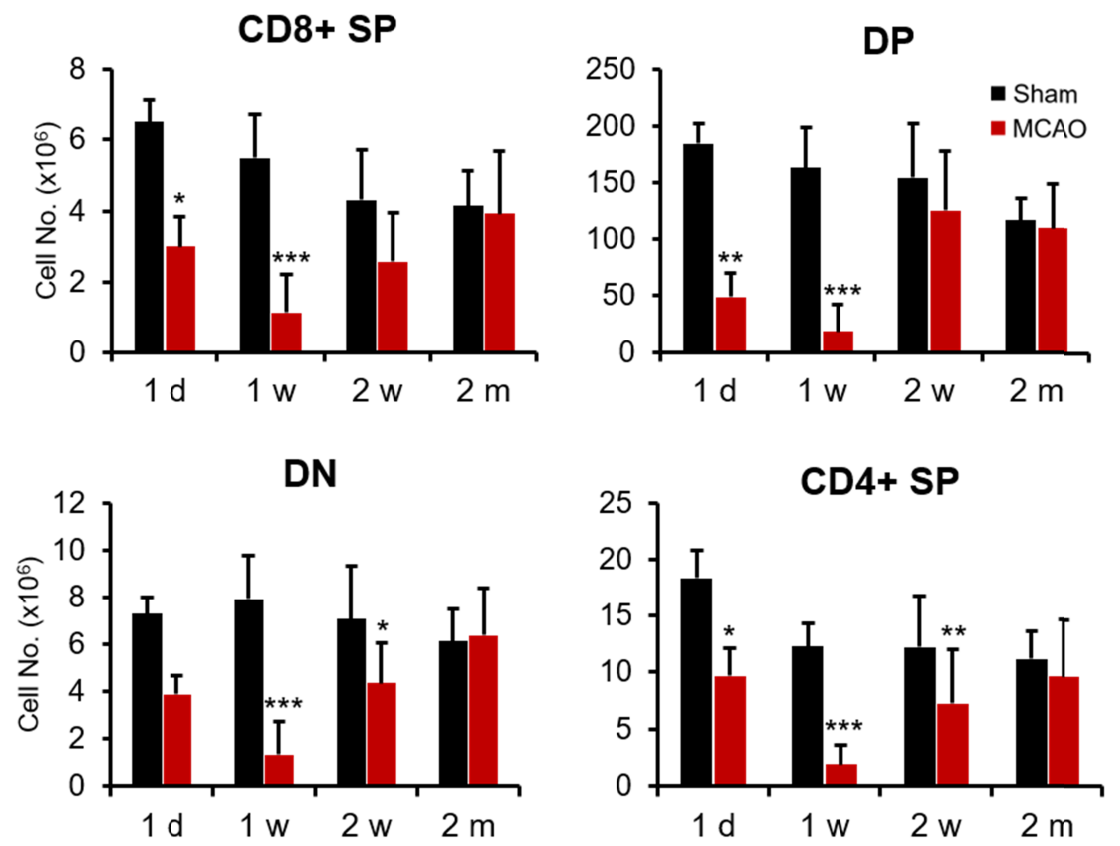

Fig. 2. Total cell number and subpopulation of thymocytes after tMCAO. (A) Representative thymus size and morphology at one and two weeks. (B) Total thymocyte numbers were counted. (C) CD4 and CD8 thymocytes were analyzed using flow cytometry. Numbers marked in red in the FACS data represent values that differ from those of sham-operated mice. (D) Absolute thymocyte numbers for each subpopulation were counted. Numbers of mice were ( $n=$ sham/tMCAO): $1 \mathrm{~d}(\mathrm{n}=6 / 8), 1 \mathrm{w}(\mathrm{n}=9 / 9), 2 \mathrm{w}(\mathrm{n}=10 / 13), 2 \mathrm{~m}(\mathrm{n}=14 / 16)$, and $6 \mathrm{~m}(\mathrm{n}=9 / 26) .{ }^{*} \mathrm{p} \leq 0.05,{ }^{* *} \mathrm{p} \leq 0.01$, and ${ }^{* * *} \mathrm{p} \leq 0.001$. CD $8^{+} \mathrm{SP}$ (CD4 CD8 ${ }^{+}$single-positive), DP (CD4 ${ }^{+} \mathrm{CD}^{+}$double-positive), $\mathrm{DN}$ (CD4 CD8 double-negative), $\mathrm{CD} 4^{+} \mathrm{SP}\left(\mathrm{CD} 4^{+} \mathrm{CD} 8\right.$ single-positive). 
A
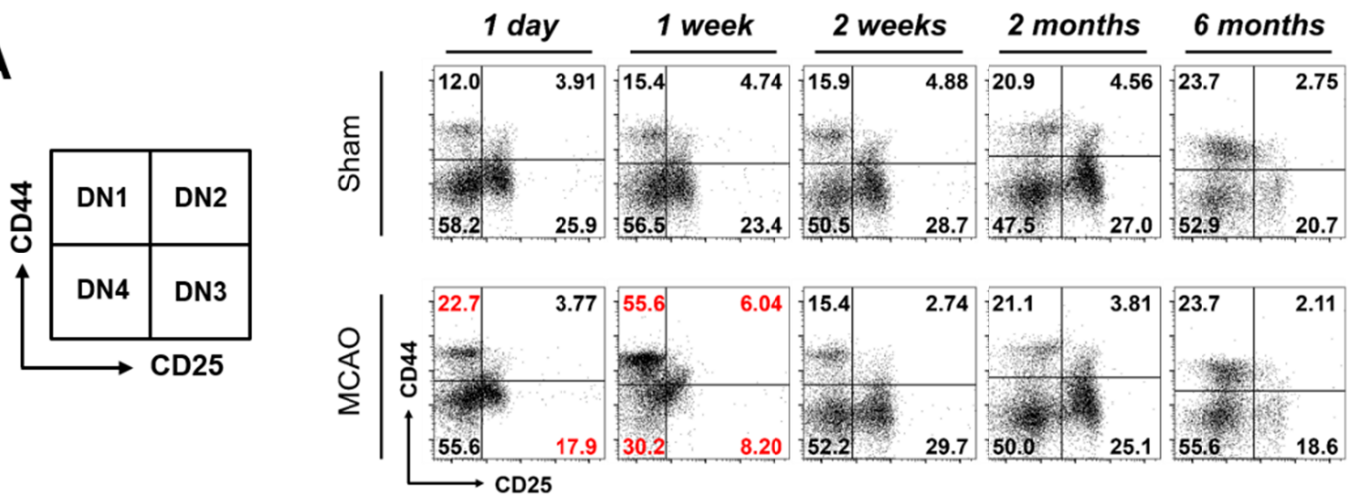

B
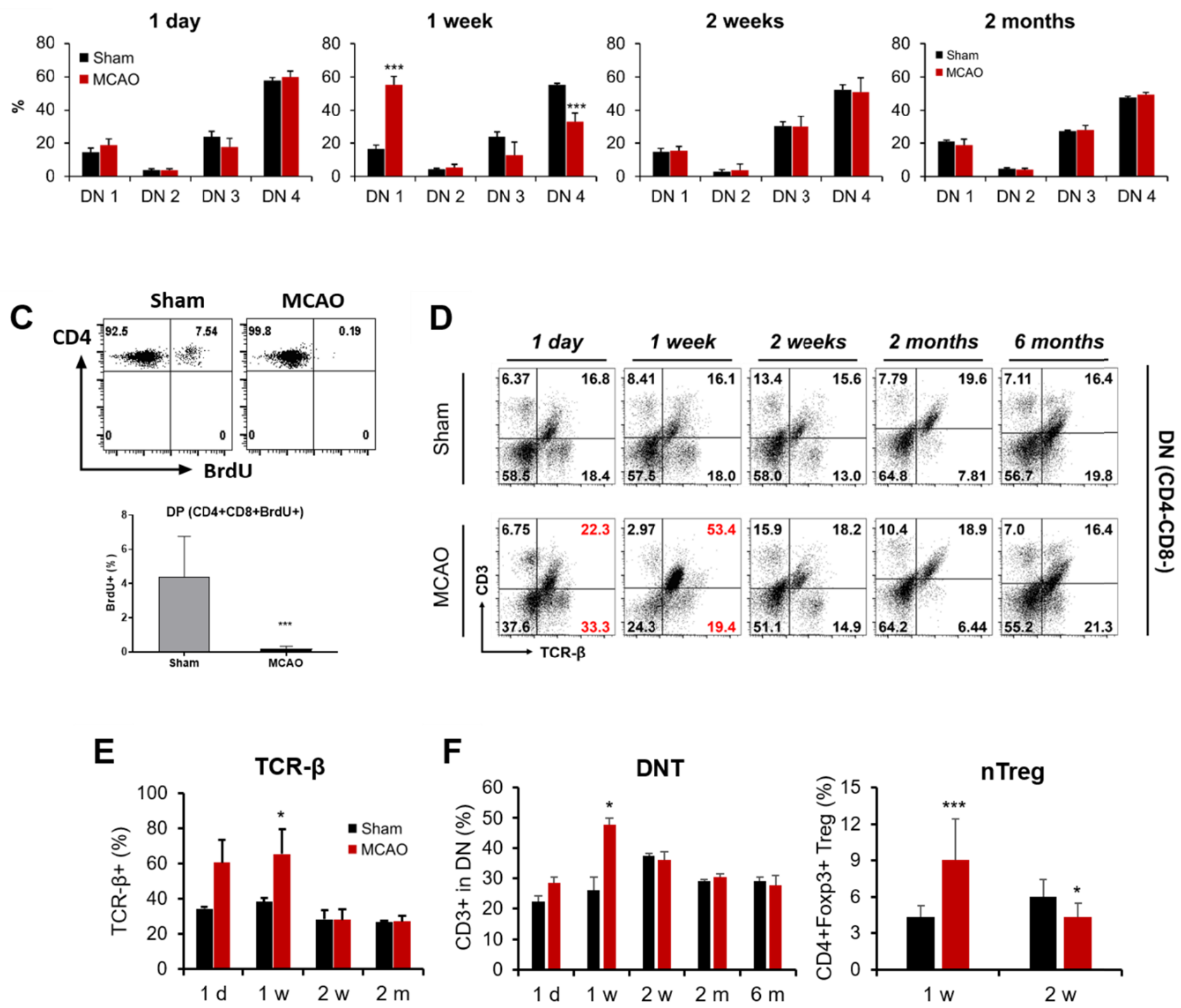

Fig. 3. Impairment of thymocyte development after tMCAO. (A) DN stages of thymocytes were analyzed according to CD44 and CD25 expression. Number marked in red in FACS data indicate values that differ from those of sham-operated mice. (B) Percentage of DN subpopulation is shown. (C) Thymocyte proliferation was measured using BrdU assay. (D, E) The percentage of TCR- $\beta$ subpopulations was analyzed in the DN population. (F) CD4 CD8 CD $3^{+}$DNT (double-negative T cell) and CD4 ${ }^{+}$Foxp $3^{+}$nTreg (natural regulatory T cell) were analyzed in thymus. Numbers of mice were ( $\mathrm{n}=\mathrm{sham} /$ tMCAO): $1 \mathrm{~d}(\mathrm{n}=6 / 8), 1 \mathrm{w}(\mathrm{n}=9 / 9), 2 \mathrm{w}(\mathrm{n}=11 / 17), 2 \mathrm{~m}(\mathrm{n}=14 / 16), 6 \mathrm{~m}(\mathrm{n}=9 / 29) .{ }^{*} \mathrm{p} \leq 0.05$ and ${ }^{* * *} \mathrm{p} \leq 0.001$. 
thymocyte differentiation $[18,19]$. The increased TCR- $\beta^{+}$population in the DN stage could be a reason for cell death. In addition, previous reports suggest that $\mathrm{CD} 4 \mathrm{CD} 8 \mathrm{CD}^{+} \mathrm{T}$ cells (doublenegative T cells; DNTs) in brain promote neuroinflammation after stroke, while brain Foxp $3^{+}$regulatory T cells (Treg) have neuroprotective function $[20,21]$. Therefore, we analyzed the number of these cells in the thymus. Interestingly, both populations were significantly higher in $\mathrm{TMCAO}$ mice than in sham mice one week after stroke (Fig. 3F). Probably, these cells might be generated in thymus and moved into peripheral immune system and brain after stroke.

\section{Immunosuppression of T lymphocytes in the spleen of tMCAO mice}

Consistent with the decreased total thymocyte numbers in the tMCAO mice, the spleen size and total number of splenocytes were significantly reduced up to one week after stroke (Fig. $4 \mathrm{~A} \sim \mathrm{C})$. To determine whether stroke induced the activation of $\mathrm{T}$ lymphocytes, splenocytes were analyzed with CD44 and CD62L antibodies using flow cytometry. CD44 is an effector T lymphocyte marker, and the lymph node homing receptor CD62L is a naive T lymphocyte marker. In the spleen, the percentage of CD44 ${ }^{+} \mathrm{CD} 62 \mathrm{~L}^{-}$(effector-type) $\mathrm{T}$ lymphocytes was approximately $10 \%$ lower than that in sham mice in both $\mathrm{CD}^{+}$and $\mathrm{CD} 8^{+}$populations one week after stroke (Fig. 4D). In addition, to test whether ischemic stroke downregulates $\mathrm{T}$ lymphocyte function, splenocytes were stimulated with anti-CD3 and anti-CD28 antibodies. After $48 \mathrm{~h}$, IFN- $\gamma$ expression levels were lower up to one week after stroke than those in sham mice (Fig. 4E). Consistently, the fluorescence intensity of the activated Tlymphocyte marker $\mathrm{CD} 25^{+}$was significantly lower than that in sham mice one week after stroke in $\mathrm{CD}^{+} \mathrm{T}$ lymphocytes (Fig. 4F). This suggests that stroke induced the immunosuppressive function of $\mathrm{T}$ cells in the spleen at an early stage.

\section{Increased CD44 ${ }^{+}$CD62L- Tlymphocytes in the blood of tMCAO mice}

Circulating lymphocytes in whole blood were examined. In particular, the percentage of $\mathrm{CD}^{+} \mathrm{T}$ lymphocytes was significantly lower than that in sham mice until one week after stroke (Fig. 5A and $\mathrm{B}$ ). In contrast to the spleen, the percentage of $\mathrm{CD} 44^{+} \mathrm{CD} 62 \mathrm{~L}^{-}$ effector $\mathrm{T}$ lymphocytes in the blood was elevated by approximately $10 \%$ in the $\mathrm{CD}^{+}$population until two weeks after stroke (Fig. 5C and D). Activated effector T lymphocytes probably egressed from the spleen to the bloodstream in $\mathrm{TMCAO}$ mice.

\section{Analysis of T lymphocytes in the brain of tMCAO mice}

To investigate any correlations between the thymus, spleen, blood, and brain after stroke, $\mathrm{T}$ lymphocytes in the brain were isolated using the Percoll gradient protocol and phenotypes were analyzed. The number of $\mathrm{CD}^{+} \mathrm{T}$ cells gradually increased in the brain of tMCAO mice until two weeks (Fig. 6A). The number of $\mathrm{CD}^{+}$and $\mathrm{CD}^{+}{ }^{+}$cells also gradually increased from day one to two weeks. In addition, brain $\mathrm{CD} 4 \mathrm{CD}^{-} \mathrm{CD}^{+}$double-negative $\mathrm{T}$ cells (DNTs) play an inflammatory role in brain injury [20]. The number of DNTs rapidly increased one week after the stroke (Fig. $6 \mathrm{~A}$ ). Interestingly, when we stained $\mathrm{CD}^{+} \mathrm{T}$ cells in the ipsilateral injured area, they reached a peak at one week, which was sustained for up to six months after stroke (Fig. 6B). This suggests that CD4 ${ }^{+}$ $\mathrm{T}$ cells had strongly infiltrated the injured brain area one week after stroke, and some cells were present in the tissue for up to six months. In addition, Tregs in the brain play a role in the regulation of inflammation after stroke $[21,22]$. Therefore, we analyzed the number of Foxp $3^{+}$Tregs in the brain. In the ipsilateral cortex injury area, Foxp $3^{+}$cells gradually increased for up to six months. As some Tregs express IL-10 cytokines, we stained to assess expression of both Foxp3 and IL-10 in the infarct area. IL-10 expression strongly increased from two weeks to six months, and the expression of co-localized cells with Foxp3 also increased (Fig. 7). This suggests that the increased levels of IL-10-producing Tregs in the injured area may inhibit inflammation, which may be correlated with increased T lymphocytes and recovery of NSS and body weight.

\section{DISCUSSION}

Here, we aimed to provide a system-based assessment of peripheral responses to cerebral ischemia and show dynamic $\mathrm{T}$ cell movement and roles beyond the brain from one day up to six months post-stroke. In our stroke model, the largest infarct size (IS) was observed one week post-stroke and gradually decreased up to six months, whereas the EI size did not decrease. This means that the reduction in the infarct area does not necessarily indicate the recovery of neuronal cells from two weeks after tMCAO. However, consistent with the IS, the body weight and NSS recovered from two weeks post-stroke, which was associated with the recovery of T lymphocytes. Interestingly, NSS gradually recovered from two weeks to six months, which was associated with increased number of IL- $10^{+}$Foxp 3 regulatory cells in the brain. The recovery of T lymphocyte numbers and increased IL- $10^{+} \mathrm{Foxp}^{+}$regulatory $\mathrm{T}$ lymphocytes may be important for long-term neurological outcomes.

Lymphocyte number and IFN- $\gamma$ production decreased up to 
A

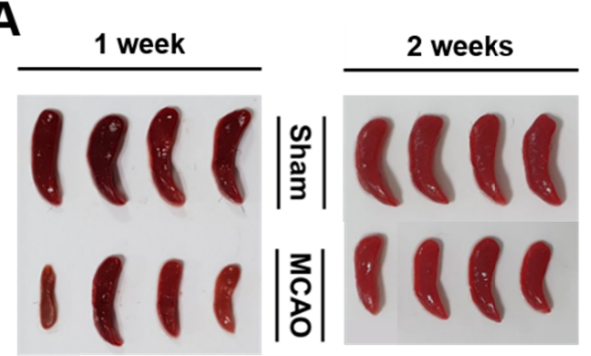

C

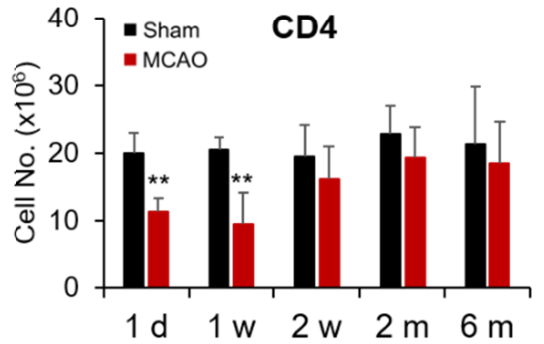

D
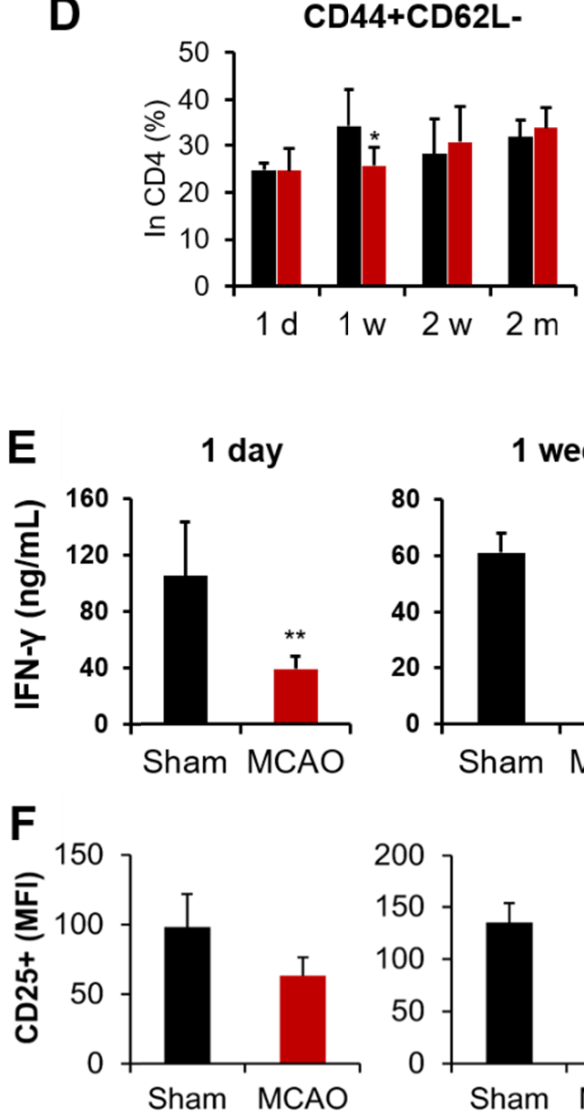

B
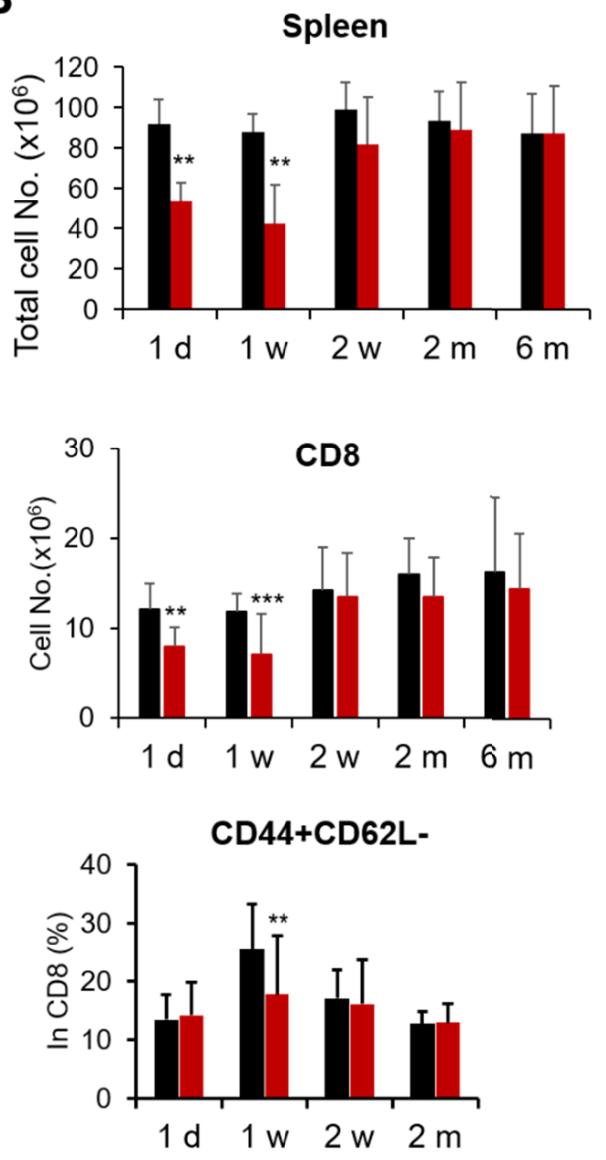

2 weeks

2 months
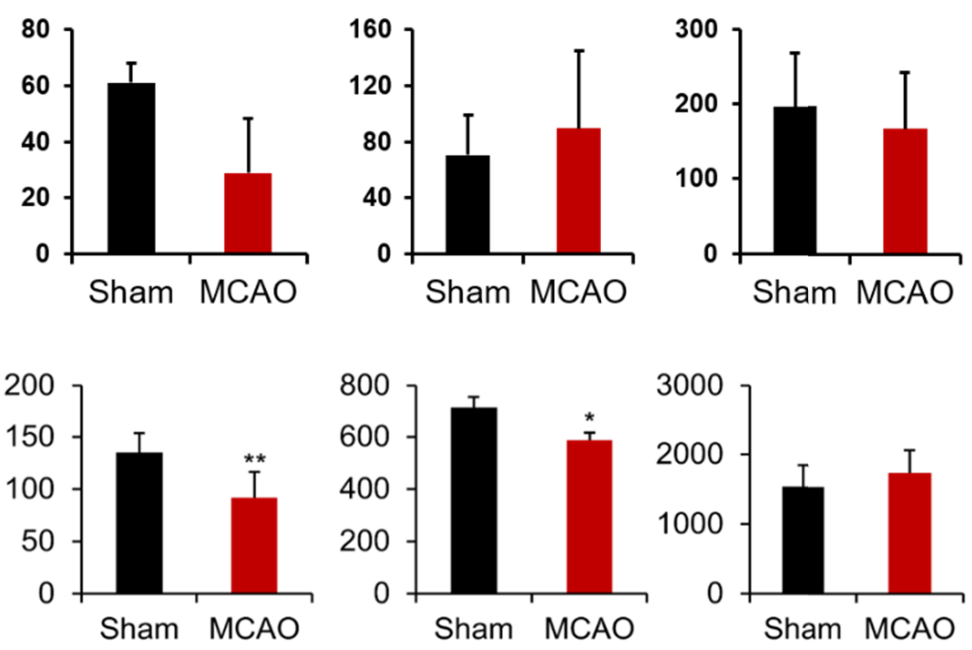

Fig. 4. T lymphocyte population and phenotype in the spleen after tMCAO. (A) Representative spleen size and morphological analysis for sham and tMCAO mice at one and two weeks after stroke. (B) Total cell number and (C) $\mathrm{CD}^{+}$and $\mathrm{CD} 8^{+} \mathrm{T}$ lymphocytes were counted. (D) CD44 ${ }^{+} \mathrm{CD} 62 \mathrm{~L}$ effector cells were analyzed in $\mathrm{CD}^{+}$and $\mathrm{CD}^{+}$T lymphocytes. Mice numbers were $(\mathrm{n}=\mathrm{sham} / \mathrm{tMCAO}): 1 \mathrm{~d}(\mathrm{n}=6 / 7), 1 \mathrm{w}(\mathrm{n}=6 / 9), 2 \mathrm{w}(\mathrm{n}=8 / 12), 2 \mathrm{~m}(\mathrm{n}=13 / 15)$, and $6 \mathrm{~m}(\mathrm{n}=7 / 26)$. (E) Splenocytes were stimulated with $0.1 \mu \mathrm{g} / \mathrm{ml} \alpha-C D 3$ and $\alpha-C D 28$ antibodies. IFN- $\gamma(\mathrm{ng} / \mathrm{ml})$ levels in the cell culture supernatant were measured using ELISA after $48 \mathrm{~h}$ of stimulation. (F) The stimulated T lymphocytes were stained with CD4 and CD25 antibodies, and their fluorescence intensities were analyzed using flow cytometry. Mice numbers were ( $\mathrm{n}=\mathrm{sham} / \mathrm{tMCAO}): 1 \mathrm{~d}(\mathrm{n}=5 / 7), 1 \mathrm{w}(\mathrm{n}=4 / 3), 2 \mathrm{w}(\mathrm{n}=5 / 5)$, and $2 \mathrm{~m}(\mathrm{n}=7 / 6)$. ${ }^{*} \mathrm{p} \leq 0.05,{ }^{* *} \mathrm{p} \leq 0.01$, and ${ }^{* * *} \mathrm{p} \leq 0.001$. 
A
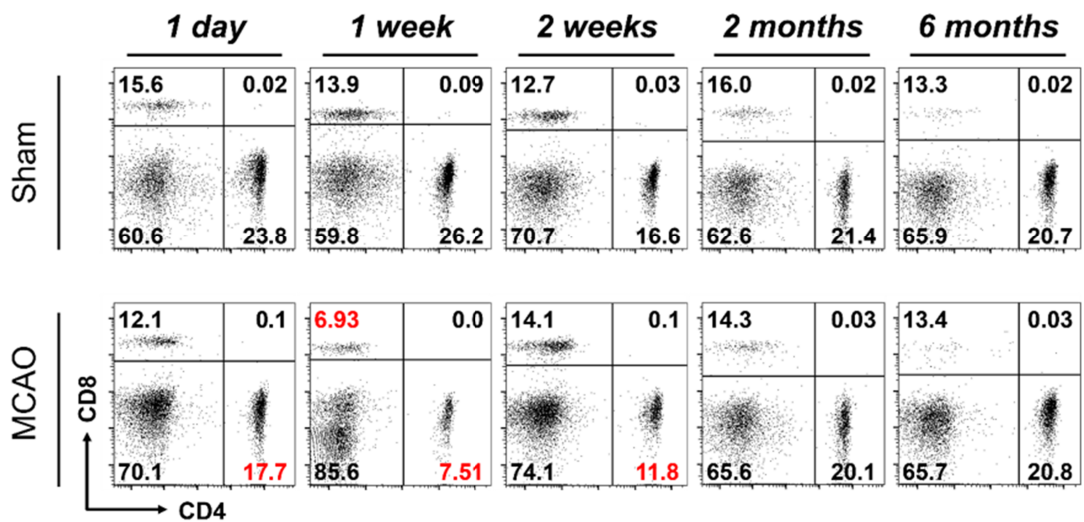

B
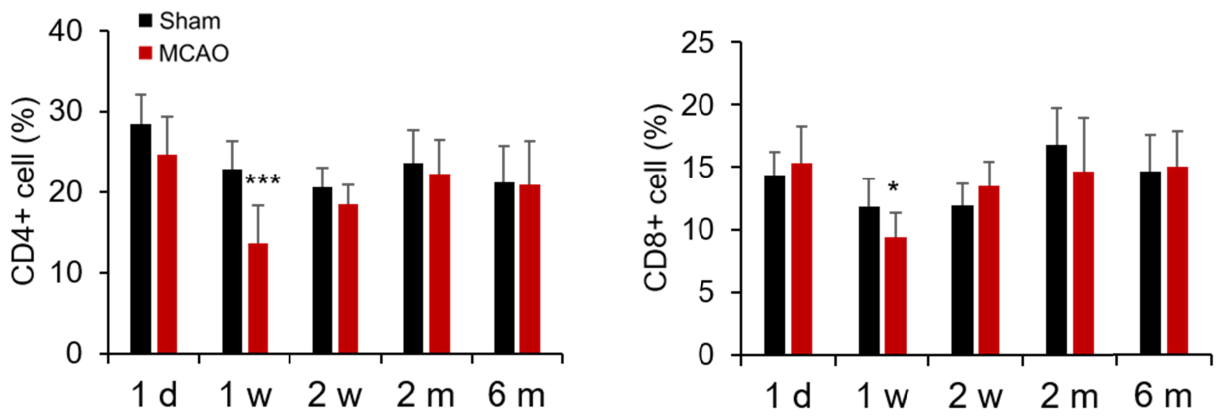

C
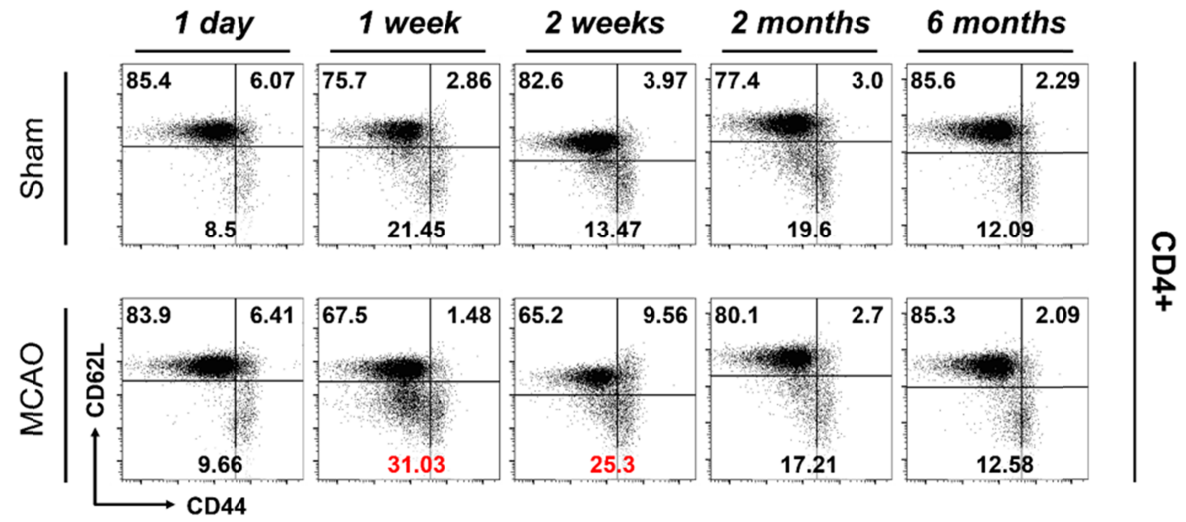

D

CD44+CD62L-

CD44+CD62L-
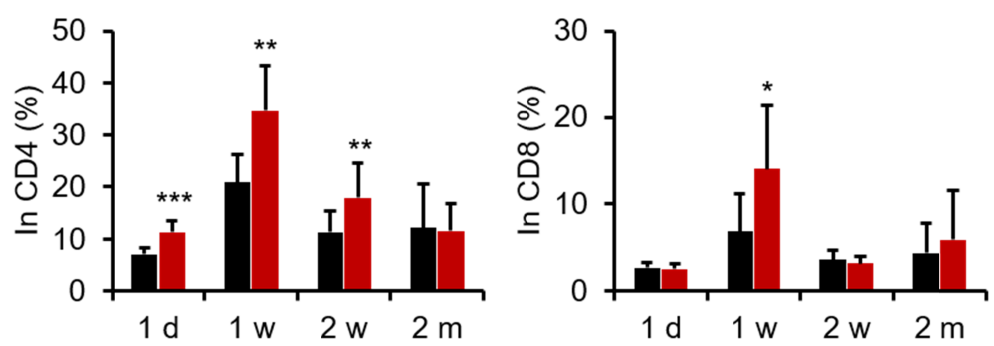

Fig. 5. T lymphocyte population and phenotype in the blood after tMCAO. (A) Representative CD4 and CD8 T lymphocyte population plots are shown. Numbers marked in red in the FACS data represent values that differ from those for sham mice. (B) Percentages of CD $4^{+}$and CD $8^{+} \mathrm{T}$ lymphocytes subpopulations were analyzed. (C, D) CD44 CD62 L effector cells were analyzed in T lymphocytes. Mice numbers were ( $\mathrm{n}=\mathrm{sham} / \mathrm{tMCAO}): 1 \mathrm{~d}$ $(\mathrm{n}=8 / 8), 1 \mathrm{w}(\mathrm{n}=8 / 7), 2 \mathrm{w}(\mathrm{n}=11 / 12), 2 \mathrm{~m}(\mathrm{n}=15 / 13)$, and $6 \mathrm{~m}(\mathrm{n}=9 / 29) .{ }^{*} \mathrm{p} \leq 0.05,{ }^{* *} \mathrm{p} \leq 0.01$, and ${ }^{* * *} \mathrm{p} \leq 0.001$. 
A

CD3+
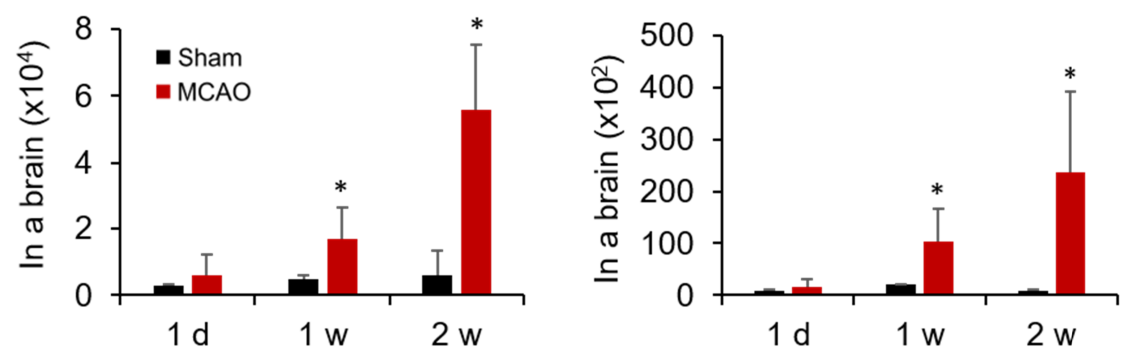

CD4+

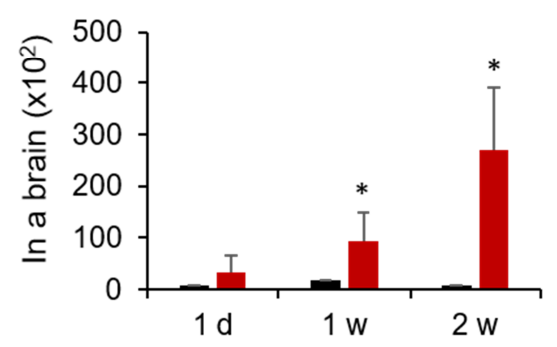

CD8+

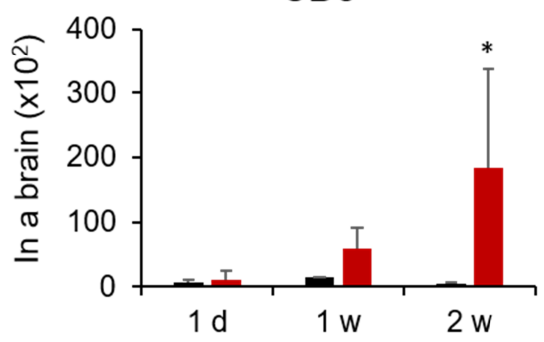

B

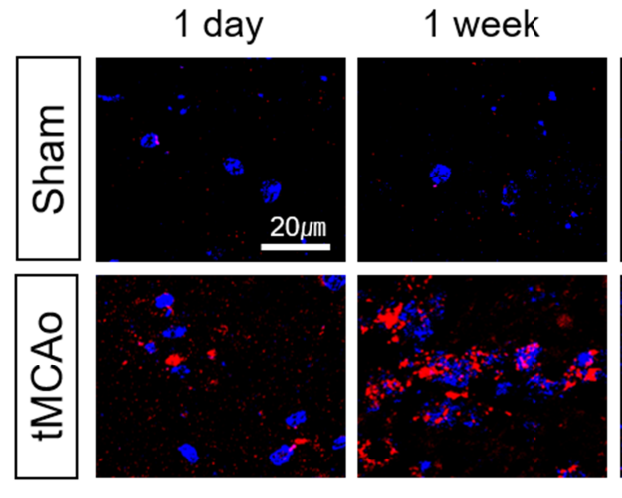

\section{2 weeks}

2 month
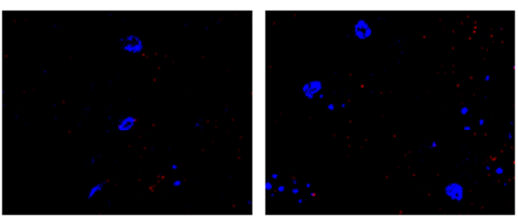

6 month

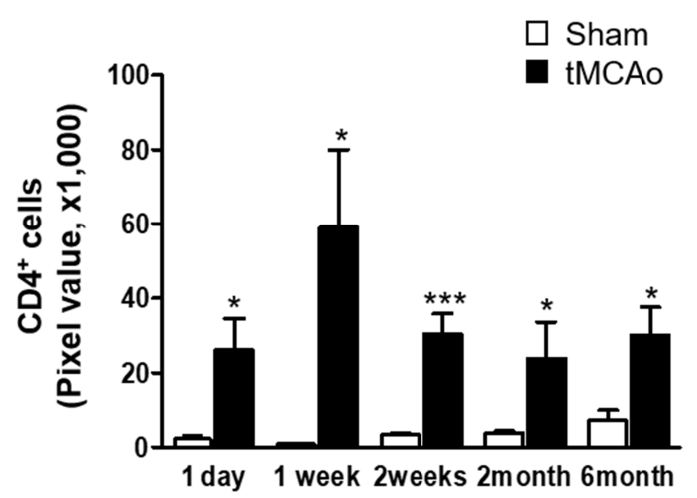

Fig. 6. Analysis of brain T cells after tMCAO. (A) Absolute cell numbers of brain $\mathrm{CD} 3^{+} \mathrm{T}$ cells, DNTs, CD4 ${ }^{+}$, and $\mathrm{CD} 8^{+} \mathrm{T}$ cells were analyzed using FACS. To obtain the required cell numbers, brain T cells were analyzed by pooling samples from the ipsilateral hemispheres. A total of $4 \sim 8$ brains were combined per sample from sham-operated mice and 2 4 brains were combined per sample from tMCAO mice. The number of independent experiments was three at one day and two weeks and four at one week. All data were pooled for analysis. Mice numbers were $(\mathrm{n}=\mathrm{sham} / \mathrm{tMCAO}): 1 \mathrm{~d}(\mathrm{n}=5 / 9), 1$ $\mathrm{w}(\mathrm{n}=27 / 17)$, and $2 \mathrm{w}(\mathrm{n}=18 / 18)$. (B) Brain tissues were processed for immunohistochemical analysis from one day to six months post-tMCAO. Fluorescence images of CD4 (red) and DAPI (blue). Quantification of CD4 levels in the striatum of mouse with tMCAO. Scale bar $=20 \mu \mathrm{m}$. Mice numbers were $(\mathrm{n}=\operatorname{sham} / \mathrm{tMCAO}): 1 \mathrm{~d}(\mathrm{n}=3 / 3) ; 1 \mathrm{w}(\mathrm{n}=3 / 3), 2 \mathrm{w}(\mathrm{n}=5 / 3), 2 \mathrm{~m}(\mathrm{n}=5 / 6)$, and $6 \mathrm{~m}(\mathrm{n}=4 / 11){ }^{*} \mathrm{p} \leq 0.05$ and $^{* * *} \mathrm{p} \leq 0.001$. 

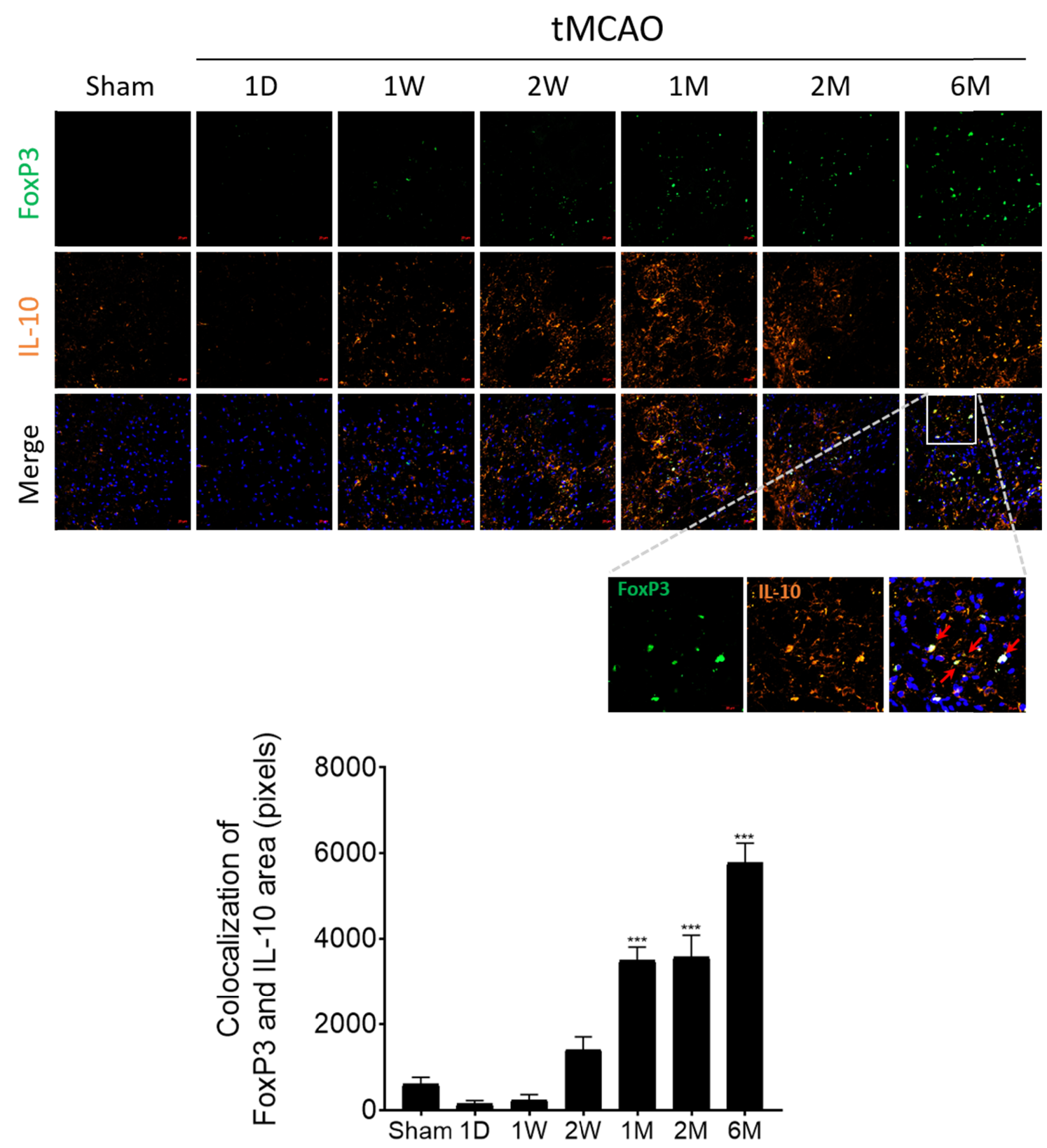

Fig. 7. Analysis of IL- $10^{+}$Foxp $3^{+}$Tregs in the brain. Brain tissues were processed for immunohistochemical analysis at one day to six months posttMCAO. Fluorescence images of Foxp3 (green), IL-10 (orange), and DAPI (blue). A white square was expanded in a large image of the ischemic region.

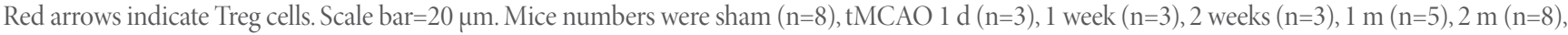
and $6 \mathrm{~m}(\mathrm{n}=6){ }^{* * *} \mathrm{p} \leq 0.001$.

two weeks post-stroke, in which the $\beta 2$-adrenoreceptor antagonist propranolol and the glucocorticoid receptor inhibitor RU486 are involved in the recovery of early lymphocyte activation [17]. However, a detailed analysis of T lymphocytes in relation to brain damage has not yet been reported. Here, we analyzed T lymphocytes in both the lymphoid organs and brain from day one up to six months to show dynamic T lymphocyte movement. We observed a lower number of T lymphocytes up to one week post-stroke, and the number of cells recovered after two weeks. The percentage of CD44 ${ }^{+} \mathrm{CD} 62 \mathrm{~L}^{-}$effector $\mathrm{T}$ lymphocytes increased in the blood but decreased in the spleen. In addition, we observed increased levels of effector T lymphocytes in the brains of tMCAO mice (data not shown). This suggests that effector T lymphocytes egress from the spleen and enter the injury sites of the brain through the blood stream in the early stages of stroke, whereas naive T cells likely remain in the spleen. In addition, we observed decreased CD25 ex- 
pression and cytokine production (such as IFN- $\gamma$ ) up to one week post-stroke when splenocytes were stimulated with anti-CD3 and anti-CD28 antibodies.

It is likely that intrinsic TCR signaling is affected by stroke. Stress hormones, especially catecholamines released by immune cells or the HPA axis, serve as modulators to reduce lymphocyte proliferation and differentiation, and they induce cell apoptosis through the $\beta 2$-adrenergic receptor [23-25]. Here, we also observed a marked reduction in thymus size and number of thymocytes in mice following stroke. Administration of a $\beta 2$-adrenergic receptor agonist, such as isoproterenol, leads to a decrease in thymocyte number and thymus weight [26]. Moreover, glucocorticoids induce apoptosis of thymocytes in vivo and in vitro, especially in the DP population [27-29]. As T lymphocytes express catecholamine [30], the dynamic changes in catecholamine levels in immune organs and T lymphocytes post-stroke should be elucidated to understand the relationship between $\mathrm{T}$ lymphocytes and neurological disability. Moreover, we observed a developmental block in the DN stage and inhibition of thymocyte proliferation at day one post-stroke. This means that stroke induced thymocyte cell death and inhibited the development and proliferation of thymocytes in the acute phase. This phenomenon appears to be one of the reasons for $\mathrm{T}$ lymphocyte loss in the peripheral immune system. Various selection mechanisms operate in the thymus and negative selection causes apoptosis of thymocytes with high TCR gene expression [31-33]. Thymocytes with high avidity TCR/ligand interactions undergo thymic selection because of mutual antagonism between TCR-mediated signals and glucocorticoids in the thymus [34-36]. It is possible that stroke-induced glucocorticoids increase TCR- $\beta$ expression and induce the death of immature thymocytes through negative selection in the thymus. As glucocorticoid metabolic enzymes are expressed in thymocyte subsets [35], whether stroke can affect these enzymes requires further investigation.

Recently, several studies have reported the various roles of infiltrating T lymphocytes in the brain following stroke [37-39]. Infiltrating DNTs promote microglia-mediated neuroinflammation and increase brain injury in the acute phase following stroke [20]. However, where the DNTs in brain injury sites following a stroke are primarily derived from is currently unclear. We found that the number of DNTs and $\mathrm{CD}^{+}$and $\mathrm{CD}^{+} \mathrm{T}$ cells in the brain increased gradually from one to two weeks following a stroke. We also observed an increase in the percentage of DNTs in the thymus one week post-stroke. Moreover, we observed an increased number of brain $\mathrm{CD}^{+} \mathrm{CD} 4^{+} \mathrm{Foxp} 3^{+}$Treg cells in the chronic phase up to six months post-stroke. Ito et al. found that brain Treg cell numbers increased from 10 days after stroke, which may potentiate neurological recovery during the chronic phase [21]. They also reported that brain Treg cells are thymus-derived effector cells. We also observed increases in $\mathrm{CD}^{+} \mathrm{Foxp}^{+}{ }^{+}$nTreg cells in the thymus and gradual increases in the number of IL- $10^{+} \mathrm{Foxp} 3^{+}$Treg cells in the brain, which may be associated with the improved NSS. Therefore, the exact role of this population should be investigated in future studies to identify potential therapeutic targets. Overall, T lymphocytes have different infiltration time points to the site of brain injury following a stroke, depending on their pro- or antiinflammatory functions. The spleen in a mouse contains approximately $30 \%$ of T cells. The outcomes of stroke after splenectomy differ depending on splenectomy time, sex, and rodent species $[40,41]$. In a mouse model, splenectomy immediately before MCAO did not improve outcomes [42]. Male mice were protected by splenectomy two weeks before MCAO but female mice were not [43]. Female mice had more regulatory $\mathrm{T}$ lymphocytes than males, whereas male mice had more activated $\mathrm{T}$ lymphocytes in the spleen [43]. In a rat model, a recent report showed that delayed splenectomy failed to provide long-term protection to the ischemic brain or improve functional recovery, such as the recovery of sensorimotor and cognitive function $[40,44]$. The authors suggest that the loss of neuroprotection might be related to a prolonged decrease in the proportion of $\mathrm{T}$ cells. In studies with stroke patients, the proportion of circulating T lymphocytes was significantly lower than that in healthy controls $[45,46]$. Similar to the rodent model, the frequencies of $\mathrm{T}$ lymphocytes were negatively correlated with stroke severity at onset, and a loss of CD4 ${ }^{+} \mathrm{T}$ cells was related to stroke-induced immunosuppression $[45,46]$. However, long-term changes in T lymphocytes after stroke have not been well studied in humans. Our results suggest that activated T lymphocytes play a detrimental role in the early stages of stroke, and regulatory $\mathrm{T}$ lymphocytes may have a protective role in longterm recovery. Considering the large number of patients with post-stroke disorders, studies of the chronic phase are of great importance. Therefore, our study provides fundamental information regarding T lymphocyte alterations in the brain and peripheral tissues from the acute to chronic phase of stroke, which may be helpful for developing potential therapeutic targets for stroke.

\section{ACKNOWLEDGEMENTS}

This study was supported by the Brain Research Program through the NRF of Korea (NRF- NRF-2017M3C7A1031102, NRF-2017M3C7A1031105, and NRF-2017M3C7A1031108).

\section{REFERENCES}

1. Anrather J, Iadecola C (2016) Inflammation and stroke: an 
overview. Neurotherapeutics 13:661-670.

2. Emsley HC, Hopkins SJ (2008) Acute ischaemic stroke and infection: recent and emerging concepts. Lancet Neurol 7:341-353.

3. McColl BW, Allan SM, Rothwell NJ (2009) Systemic infection, inflammation and acute ischemic stroke. Neuroscience 158:1049-1061.

4. McColl BW, Rothwell NJ, Allan SM (2007) Systemic inflammatory stimulus potentiates the acute phase and CXC chemokine responses to experimental stroke and exacerbates brain damage via interleukin-1- and neutrophil-dependent mechanisms. J Neurosci 27:4403-4412.

5. Elkind MS, Cheng J, Rundek T, Boden-Albala B, Sacco RL (2004) Leukocyte count predicts outcome after ischemic stroke: the Northern Manhattan Stroke study. J Stroke Cerebrovasc Dis 13:220-227.

6. Offner H, Subramanian S, Parker SM, Wang C, Afentoulis ME, Lewis A, Vandenbark AA, Hurn PD (2006) Splenic atrophy in experimental stroke is accompanied by increased regulatory $\mathrm{T}$ cells and circulating macrophages. J Immunol 176:6523-6531.

7. Chiu NL, Kaiser B, Nguyen YV, Welbourne S, Lall C, Cramer SC (2016) The volume of the spleen and its correlates after acute stroke. J Stroke Cerebrovasc Dis 25:2958-2961.

8. Ajmo CT Jr, Vernon DO, Collier L, Hall AA, GarbuzovaDavis S, Willing A, Pennypacker KR (2008) The spleen contributes to stroke-induced neurodegeneration. J Neurosci Res $86: 2227-2234$.

9. Chauhan A, Al Mamun A, Spiegel G, Harris N, Zhu L, McCullough LD (2018) Splenectomy protects aged mice from injury after experimental stroke. Neurobiol Aging 61:102111.

10. Hurn PD, Subramanian S, Parker SM, Afentoulis ME, Kaler LJ, Vandenbark AA, Offner H (2007) T- and B-cell-deficient mice with experimental stroke have reduced lesion size and inflammation. J Cereb Blood Flow Metab 27:1798-1805.

11. Yilmaz G, Arumugam TV, Stokes KY, Granger DN (2006) Role of T lymphocytes and interferon-gamma in ischemic stroke. Circulation 113:2105-2112.

12. Cao Y, Sun N, Yang JW, Zheng Y, Zhu W, Zhang ZH, Wang XR, Shi GX, Liu CZ (2017) Does acupuncture ameliorate motor impairment after stroke? An assessment using the CatWalk gait system. Neurochem Int 107:198-203.

13. Combs DJ, D'Alecy LG (1987) Motor performance in rats exposed to severe forebrain ischemia: effect of fasting and 1,3-butanediol. Stroke 18:503-511.

14. Yang J, Ahn HN, Chang M, Narasimhan P, Chan PH, Song YS
(2013) Complement component 3 inhibition by an antioxidant is neuroprotective after cerebral ischemia and reperfusion in mice. J Neurochem 124:523-535.

15. Pino PA, Cardona AE (2011) Isolation of brain and spinal cord mononuclear cells using percoll gradients. J Vis Exp (48):2348.

16. Kim E, Woo MS, Qin L, Ma T, Beltran CD, Bao Y, Bailey JA, Corbett D, Ratan RR, Lahiri DK, Cho S (2015) Daidzein augments cholesterol homeostasis via ApoE to promote functional recovery in chronic stroke. J Neurosci 35:15113-15126.

17. Prass K, Meisel C, Höflich C, Braun J, Halle E, Wolf T, Ruscher K, Victorov IV, Priller J, Dirnagl U, Volk HD, Meisel A (2003) Stroke-induced immunodeficiency promotes spontaneous bacterial infections and is mediated by sympathetic activation reversal by poststroke T helper cell type 1-like immunostimulation. J Exp Med 198:725-736.

18. Savino W (2006) The thymus is a common target organ in infectious diseases. PLoS Pathog 2:e62.

19. Starr TK, Jameson SC, Hogquist KA (2003) Positive and negative selection of T cells. Annu Rev Immunol 21:139-176.

20. Meng H, Zhao H, Cao X, Hao J, Zhang H, Liu Y, Zhu MS, Fan L, Weng L, Qian L, Wang X, Xu Y (2019) Double-negative T cells remarkably promote neuroinflammation after ischemic stroke. Proc Natl Acad Sci U S A 116:5558-5563.

21. Ito M, Komai K, Mise-Omata S, Iizuka-Koga M, Noguchi Y, Kondo T, Sakai R, Matsuo K, Nakayama T, Yoshie O, Nakatsukasa H, Chikuma S, Shichita T, Yoshimura A (2019) Brain regulatory $\mathrm{T}$ cells suppress astrogliosis and potentiate neurological recovery. Nature 565:246-250.

22. Liesz A, Suri-Payer E, Veltkamp C, Doerr H, Sommer C, Rivest S, Giese T, Veltkamp R (2009) Regulatory T cells are key cerebroprotective immunomodulators in acute experimental stroke. Nat Med 15:192-199.

23. Bergquist J, Tarkowski A, Ekman R, Ewing A (1994) Discovery of endogenous catecholamines in lymphocytes and evidence for catecholamine regulation of lymphocyte function via an autocrine loop. Proc Natl Acad Sci U S A 91:1291212916.

24. Meisel C, Schwab JM, Prass K, Meisel A, Dirnagl U (2005) Central nervous system injury-induced immune deficiency syndrome. Nat Rev Neurosci 6:775-786.

25. Schulze J, Vogelgesang A, Dressel A (2014) Catecholamines, steroids and immune alterations in ischemic stroke and other acute diseases. Aging Dis 5:327-339.

26. Durant $S$ (1986) In vivo effects of catecholamines and glucocorticoids on mouse thymic cAMP content and thymolysis. Cell Immunol 102:136-143. 
27. Brewer JA, Kanagawa O, Sleckman BP, Muglia LJ (2002) Thymocyte apoptosis induced by $\mathrm{T}$ cell activation is mediated by glucocorticoids in vivo. J Immunol 169:1837-1843.

28. Herold MJ, McPherson KG, Reichardt HM (2006) Glucocorticoids in T cell apoptosis and function. Cell Mol Life Sci 63:60-72.

29. Wang D, Müller N, McPherson KG, Reichardt HM (2006) Glucocorticoids engage different signal transduction pathways to induce apoptosis in thymocytes and mature T cells. J Immunol 176:1695-1702.

30. Laukova M, Vargovic P, Vlcek M, Lejavova K, Hudecova S, Krizanova O, Kvetnansky R (2013) Catecholamine production is differently regulated in splenic T- and B-cells following stress exposure. Immunobiology 218:780-789.

31. Baldwin KK, Trenchak BP, Altman JD, Davis MM (1999) Negative selection of T cells occurs throughout thymic development. J Immunol 163:689-698.

32. Kurd N, Robey EA (2016) T-cell selection in the thymus: a spatial and temporal perspective. Immunol Rev 271:114-126.

33. Van De Wiele CJ, Marino JH, Murray BW, Vo SS, Whetsell ME, Teague TK (2004) Thymocytes between the beta-selection and positive selection checkpoints are nonresponsive to IL-7 as assessed by STAT-5 phosphorylation. J Immunol 172:4235-4244.

34. Vacchio MS, Papadopoulos V, Ashwell JD (1994) Steroid production in the thymus: implications for thymocyte selection. J Exp Med 179:1835-1846.

35. Rocamora-Reverte L, Reichardt HM, Villunger A, Wiegers G (2017) T-cell autonomous death induced by regeneration of inert glucocorticoid metabolites. Cell Death Dis 8:e2948.

36. Mittelstadt PR, Taves MD, Ashwell JD (2018) Cutting edge: de novo glucocorticoid synthesis by thymic epithelial cells regulates antigen-specific thymocyte selection. J Immunol
200:1988-1994.

37. Brait VH, Arumugam TV, Drummond GR, Sobey CG (2012) Importance of $\mathrm{T}$ lymphocytes in brain injury, immunodeficiency, and recovery after cerebral ischemia. J Cereb Blood Flow Metab 32:598-611.

38. Jian Z, Liu R, Zhu X, Smerin D, Zhong Y, Gu L, Fang W, Xiong $X(2019)$ The involvement and therapy target of immune cells after ischemic stroke. Front Immunol 10:2167.

39. Selvaraj UM, Stowe AM (2017) Long-term T cell responses in the brain after an ischemic stroke. Discov Med 24:323-333.

40. Zierath D, Shen A, Stults A, Olmstead T, Becker KJ (2017) Splenectomy does not improve long-term outcome after stroke. Stroke 48:497-500.

41. Seifert HA, Offner H (2018) The splenic response to stroke: from rodents to stroke subjects. J Neuroinflammation 15:195.

42. Kim E, Yang J, Beltran CD, Cho S (2014) Role of spleen-derived monocytes/macrophages in acute ischemic brain injury. J Cereb Blood Flow Metab 34:1411-1419.

43. Dotson AL, Wang J, Saugstad J, Murphy SJ, Offner H (2015) Splenectomy reduces infarct volume and neuroinflammation in male but not female mice in experimental stroke. J Neuroimmunol 278:289-298.

44. Ran Y, Liu Z, Huang S, Shen J, Li F, Zhang W, Chen C, Geng X, Ji Z, Du H, Hu X (2018) Splenectomy fails to provide longterm protection against ischemic stroke. Aging Dis 9:467-479.

45. Wang Y, Liu J, Wang X, Liu Z, Li F, Chen F, Geng X, Ji Z, Du H, Hu X (2017) Frequencies of circulating B- and T-lymphocytes as indicators for stroke outcomes. Neuropsychiatr Dis Treat 13:2509-2518.

46. Vogelgesang A, Grunwald U, Langner S, Jack R, Bröker BM, Kessler C, Dressel A (2008) Analysis of lymphocyte subsets in patients with stroke and their influence on infection after stroke. Stroke 39:237-241. 